\title{
Multimodal Sentiment Analysis Of 2020 Endsars' Lekki Massacre
}

\author{
Ajepe, Ife Fiyinfolu ${ }^{1 *}$, Aroge, Modupe Grace ${ }^{2}$ \\ ${ }^{1}$ AfeBabalola University, Ado Ekiti, Ekiti State. \\ ${ }^{2}$ ObefemiAwolowo University, Ile-Ife, Osun State.
}

*Corresponding Authors: Ajepe, Ife Fiyinfolu, AfeBabalola University, Ado Ekiti, Ekiti State, Nigeria

\begin{abstract}
The study examines BBC's reports on 2020 Lekki massacre of Nigeria youths during Endsars protest through multimodal sentiment analysis. Through the improvement of communication technology, existence of many android phones and the rapid increase of social media, a larger amount of data is being uploaded in the Internet for researchers, general populace tend to record their views and opinions on whatever their friends or relatives posted to them using a web camera and upload them on social media platforms such as YouTube, Whatsapp, Twitter or Facebook to inform the whole world of their views.
\end{abstract}

This study employs multimodal sentimental analysis to investigate the images and opinions of readers/viewers using Kress and van Leeuwen's (2006) framework for the grammar of visual design as well as Halliday's (1994/2009) interpersonal metafunction and Maryam's (2017) model of analysis of document level and sentence level was employed for sentiment analysis. A combination of text and images data helps to create a better emotion and sentiment analysis model. The data comprises of 30 purposively selected pictures and reports of Lekki massacre released by $B B C$ news which revealed the situation and update messages to the readers/viewers. In this paper, an overview of multimodal sentimental analysis of 2020 's Lekki massacre issues are presented. This paper reveals the document and sentence levels of sentimental analysis system that classifies the reader or viewers opinions as positive, negative and neutral.

The study further reveals the readers'/viewers' opinions on the people or the victims that died or wounded, the government and the general populace.The study pictures the opinion factor(s) (positive or negative) and ability or strength of public opinion (degree to which the word, phrase, sentence, or document in question is positive or negative) towards the Endsars protest data. The study concludes that the texts and images in the $B B C$ reports/news downloaded mutually reinforce one another to show people's state of mind. Furthermore, the study concludes that most of the analysis revealed that majority of the viewers' opinion to the contents of the extracts is that of negative opinion mining or negative sentiment value about Lekki toll gate shooting. In addition, the interpersonal relation between the participants reflects that of inequality while the power relation between the speaker and the people the message is meant for is that of unequal relation.

Keywords: sentiment, sentimental analysis, multimodal analysis, emotion, text/opinion mining

\section{INTRODUCTION}

At this present time, the use of internet and social media such as Facebook, Twitter, WhatsApp, Blogs etc. have been granting many advantages to the users to openly voice out their opinion(s) on issues affecting them. Due to this, the sentimental analysis is a mechanism that could track the mood of the people about any particular public matter. So, the idea of multimodal sentimental analysis is an emerging topic of research among the researchers' communities.

Endsars is anationwide protest against police brutality. It began on October 8, 2020, after a video emerged in early October showing police officers thought to be from the notorious special AntiRobbery squad or (SARS) allegedly shooting and killing a young man in Nigeria's Southern Delta State. This led to protesters gathering in various states including Lagos State where Lekki toll gate is situated. At Lekki toll gate, despite the instruction given to the youths to vacate the place, the aggrieved Nigeria youths turned deaf ear to government's instruction. Reports later came up that the Nigerian Army shot dead some of the peaceful Protesters but this was denied by Nigerian authorities. The protests erupted across the country calling to disband the unit. The unrest across Nigeria continued for days and a lot of public, government, and private properties were destroyed. About 180,000 people later signed a petition calling for the UK government to implement sanction against 
the Nigeria government and officials. In response to the call of Nigerians to the outside world, Joe Biden U.S presidential candidate urged Nigeria authorities to cease the "violent cracked down on protesters" while former presidential candidate, Hillary Clinton tweeted challenging Nigeria's president MuhammoduBuhari to "stop killing young Endsars protesters.

\section{SENTIMENT ANALYSIS}

Sentiment analysis can be viewed as self-operating or computerised way of analysing attitudes, opinions, views and emotions from text, speech, tweets, images and database sources through (NLP)Natural Language ProcessingRajput, (2019, p.1) . Sentiment analysis involves classifying opinions in text or images into categories like "positive" or "negative" or "neutral", "structured" or "unstructured" or "heterogeneous". It's also referred as subjectivity analysis, opinion mining, and appraisal extraction. According to Tiejian\&Guandonj, (2013, P. 1) Sentiment analysis (also called opinion mining) refers to the application of natural language processing, computational linguistics, and text analytics to identify and classify subjective opinions in source materials (e.g., a document or a sentence). They further explain that sentiment analysis aims to determine the attitude of a writer with respect to some topic or the overall contextual polarity of a document. The attitude may be his or her judgment or evaluation, affective state (that is to say, the emotional state of the author when writing), or the intended emotional communication (that is to say, the emotional effect the author wishes to have on the reader the texts or viewer of the images).

Sentiment Analysis is a term that includes many tasks such as sentiment extraction, sentiment classification, subjectivity classification, summarisation of opinions or opinion spam detection, among others. Abirami\&Gayathri, (2017) explain that sentiment analysis plays a significant role in decisionmaking process to automate the extraction or classification of sentiment from sentiment reviews. It aims to analyze people's sentiments, attitudes, opinions emotions, etc. towards elements such as, products, individuals, topics organizations, and services Liu (2010, p. 1). Sentiment analysis or opinion mining is the computational study of opinions, sentiments, and emotions expressed in text Liu $(2015$, p. 1). The use of sentiment analysis is becoming more widely leveraged because the information it yields can result into both positive and negative results.

The study focused on multimodal sentimental analysis of BBC's Endsars reports downloaded from the Internet.

Olateju and Oyebode (2014) note that discourse analysis has gone beyond ordinary analysis of any written or spoken text. It has extended its tentacles to all other modes of communication which of course now gives readers or researchers a wider scope to operate in the enterprise of interpreting and analyzing any form of text in arriving at a robust meaning or the intended message. The implication of this to the present study is that multimodal sentiment analysis gives opportunity to researchers to have wider scope of analysing data.

\subsection{Multimodal Sentiment Analysis}

Multimodal sentiment analysis is a new dimension of the traditional text-based sentiment analysis, which goes beyond the analysis of texts, and includes other modalities such as audio and visual data. (Kaur\&Kautish2019, p. 1). It can be bimodal, which includes different combinations of two modalities, or trimodal, which incorporates three modalities. With the extensive amount of social media data available online in different forms such as videos and images, the conventional text-based sentiment analysis has evolved into more complex models of multimodal sentiment analysis which can be applied into virtual modes such as the analysis of YouTube movie, videos, and emotion recognition. Multimodal sentiment analysis classifies different sentiment into positive, negative, or neutral (https://en.m.wikipedia,org> wiki). The aim of multimodal sentiment analysis is to increase the rigorousness of analysis of data and achieve best result.

\section{Data Analysis Procedures}

\subsection{Theoretical Framework}

To arrive at an accurate and meaningful analysis of the data, insights were drawn from Kress and van Leeuwen's (2006) framework for the grammar of visual design as well as Halliday's (1994/2009) interpersonal metafunction. For sentiment analysis, Maryam's (2017) model of analysis of document level and sentence level was employed. There is need to review the theoretical frameworks employed in the analysis. 


\subsection{Maryam's (2017) Sentimental Analysismodel}

Sentiment analysis started in 20th century, it is one of the most interesting and growing topic for research and it consists of various methods though it is classified.Sentiment analysis can occur at different levels: document level, sentence level or aspect/feature level.(Maryam 2017, p. 1).Sentiment classifications at both the document and sentence levels are useful, but they do not find what people like or dislike, nor do they identify opinion targets.

Sentiment analysis also refers to the combination of two or more input models in order to enhance goodinterpretation of data in the analysis; an example is the combination of text and audio-visual inputs. In addition, sentiment analysis refers to finding whether sentiment of a text which is written in natural language is positive, neural or negative (Obaidat et al., 2015), this can be achieved using supervised "Corpus-based" sentiment analysis approach, which relies on manually labeled samples, unsupervised "Knowledge or Lexicon-based" sentiment analysis approach, or hybrid (both lexiconbased and corpus-based) approach.Sentiment analysis consists of various methods, techniques, and tools about detecting and extracting information, like opinions and attitudes, from any text. Likely, it has been about opinion polarity, like someone has positive, neutral, or negative opinion towards something. The main object of sentiment analysis is a product or a service whose review has to be made public on the Internet.

Sentiment analysis has three levels of classification, these are: document level. Sentence level and aspect level of classification.

\subsection{Document Level Classification}

Maryam (2017, p. 1) posits that the review one can get in a whole document expresses either a positive sentiment value, negative sentiment value or neutral sentiment value. In this process, sentiment is extracted from the entire review, and a whole opinion is classified based on the overall sentiment of the opinion holder. The goal of document level sentiment analysis is to classify a review as positive, negative, or neutral. In neutral sentiment value, the opinion in general usually means that there is no opinion about the issue. Document level classification works best when the document is written by a single person and expresses an opinion/sentiment on a single entity.

\subsection{Sentence Level Classification}

In sentence level classification, the analysis is performed on the sentences rather than performed on the whole document. Here, each of the sentencesmust show a positive sentence level sentiment, negative sentence level sentiment or neutral sentence level sentiment.

This process usually involves two steps:

- Subjectivity classification of a sentence into one of two classes: objective and subjective

- Sentiment classification of subjective sentences into two classes: positive and negative

An objective sentence presents some factual information, while a subjective sentence expresses personal feelings, views, emotions, or beliefs. Subjective sentence identification can be achieved through different methods such as Naïve Bayesian classification. However, just knowing that sentences have a positive or negative opinion is not sufficient. This is an intermediate step that helps filter out sentences with no opinions and helps determine to an extent if sentiments about entities and their aspects are positive or negative. A subjective sentence may contain multiple opinions and subjective and factual clauses.

\subsection{Aspect/Feature Level Classification}

The aspect/feature level classification provides summary of multiple reviews based on the feature based opinion in aspect level sentiment analysis. Aspect level performes three functions: (i) Identifies and extracts all the features that are commented on an object by users (ii) it indicates the polarization of opinions from the classes of features which includes positive value, negative value and neutral value (iii) relate to the group synonyms (Maryam 2017, p. 2)

\subsection{Kress G. \& Van Leeuwen's (2006) Multimodal Discourse Analysis Model}

Multimodality can be defined as a means of analysing more than one modality. Multimodal discourse analysis deals with various forms of meaning units (language, image, sound, body language, and 
spacial arrangement), and focuses on how they work together to realize communicative function. Scholars around the world, devoted much time and energy to set up their own theories of multimodal discourse analysis. The greatest contributors are Kress G. \& Van Leeuwen (2006). They, based on Halliday's three Metafunctions (1994/2009), came up with three meanings of images. Multimodal discourse analysis can be done in many ways; content analysis, conversation analysis, and social semiotic analysis belong to it; and different perspectives can be taken to analyze them. For example, we can select elements such as layout, modality, color, genre, discourse, style, etc. to do multimodal discourse analysis. Multimodal discourse analysis is a new and rapidly developing research hot spot in discourse analysis field. It has become very popular in the western world since 1990s. Multimodal discourse refers to using visual, audio, and sense multi-lingual symbol system and so on, to communicate through multi-means and symbol recourses such as character, image, sound and action.

\subsection{Semiotic Theory of Communication Functions}

In order to function as a full system of communication, the visual, like all semiotic modes, has to serve several representational and communicational requirements. Kress\& Van Leeuwen (2006) adopted the theoretical notion of 'metafunction' from the work of Halliday (1994/2009) for the semiotic landscape purpose. The three metafunctions which Halliday posits are the ideational, the interpersonal and the textual. Halliday (1994, p. 36) defines interpersonal relationship as enacting social relationship. Also, Matthiessen (1995, p. 784) explains that interpersonal relationship means a kind of relationship between the speaker and listeners in an interaction. Kress and Van Leeuwen (2006), explain how the three metafunctions help in interpreting semiotic modes as follows:

- The ideational metafunction

Semiotic form has to be able to constitute aspects of the world as it is experienced by people. That is, it has to be able to represent objects and their relations in a world outside the representational system. The world is of coursesemiotically represented. So, semiotic modes offer an array of choices, of different ways in which objects, and their relations to other objects and to processes, can be represented.

- The interpersonal metafunction

Semiotic mode should be able to predict the relations between the maker of a sign, and the receiver/reproducer of that sign. In other words, any semiotic mode has to be able to represent specific social relation between the text producer(s), the viewer(s) and the object(s)being represented. Like ideational metafunction, mode offers an assembling of choices for representing different 'interpersonal' relations, some of which will be favoured in one form of visual representation (e.g. images or Vectors). There may be sense of interaction between the text maker and the viewer and on the other hand, visual representation may convey the absence of a sense of interaction.

- The textual metafunction

In textual metafunction, semiotic mode has the ability or power to construct texts which cohere both within the text and outside the context in and for which they were produced.

\section{Methodology}

The study employed survey and comparative analysis of data with the view to examine the opinion mining through the use of document and sentence levels of analysis. The analysis of the data is qualitative in nature. The qualitative method allows for flexibility. Hence, the combination of the multimodal and sentiment methods of analysis helped in balancing the outcomes of the research

\subsection{Data Presentation}

The data comprised of 30 BBC's reports on 2020 Lekki massacre of Nigeria youths during Endsars protest downloaded from the Internet.The primary data were obtained through the internet, while the secondary data relied on books, journal articles and other useful materials downloaded from the Internet.

\section{ANALYSIS, RESUlts, FindingS AND DisCuSSiOn OF FindingS}

Extract 1 below reveals the picture of some youths standing and having fun and free day on the main road during the Endsars protest. Observing the extract at the document level of classification, the 
whole document reveals negative sentiment value, that is, the opinion of viewers and even the youths is that Lekki shooting is uncalled for and that the government should rise and do something about the request of these youths. Also, the images in Extract 1 make the messages there to be more understandable to viewers that the youths and the general public's opinion to the act of the Nigeria Army isnegative. The interpersonal relation of the semiotic modes in this extract reveals a kind of specific social relation between the text producer, the viewer and the object being represented. The youths being presented here are not ready to give up despite the killing of some of them and there is a kind of affective emotional feelings for them by the viewers.
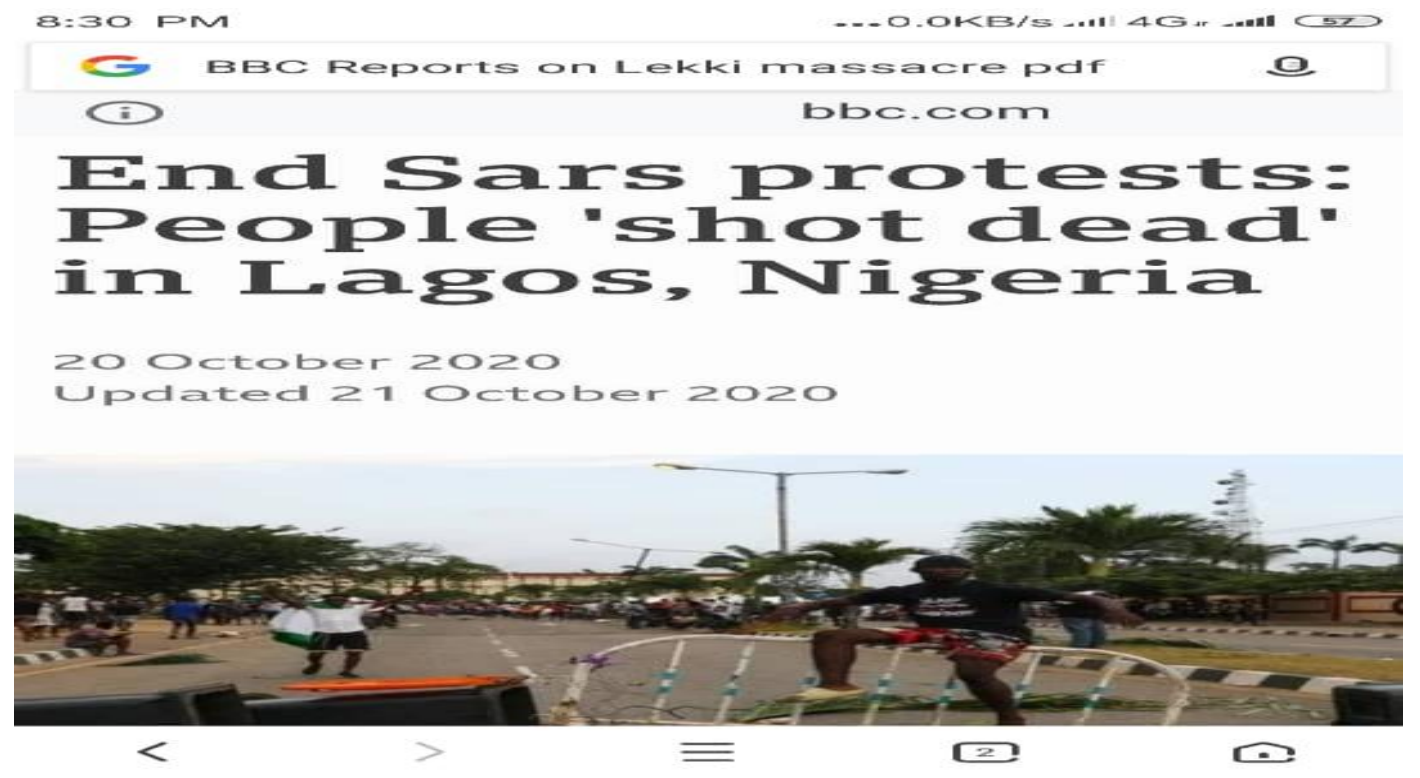

\section{Extract 1}
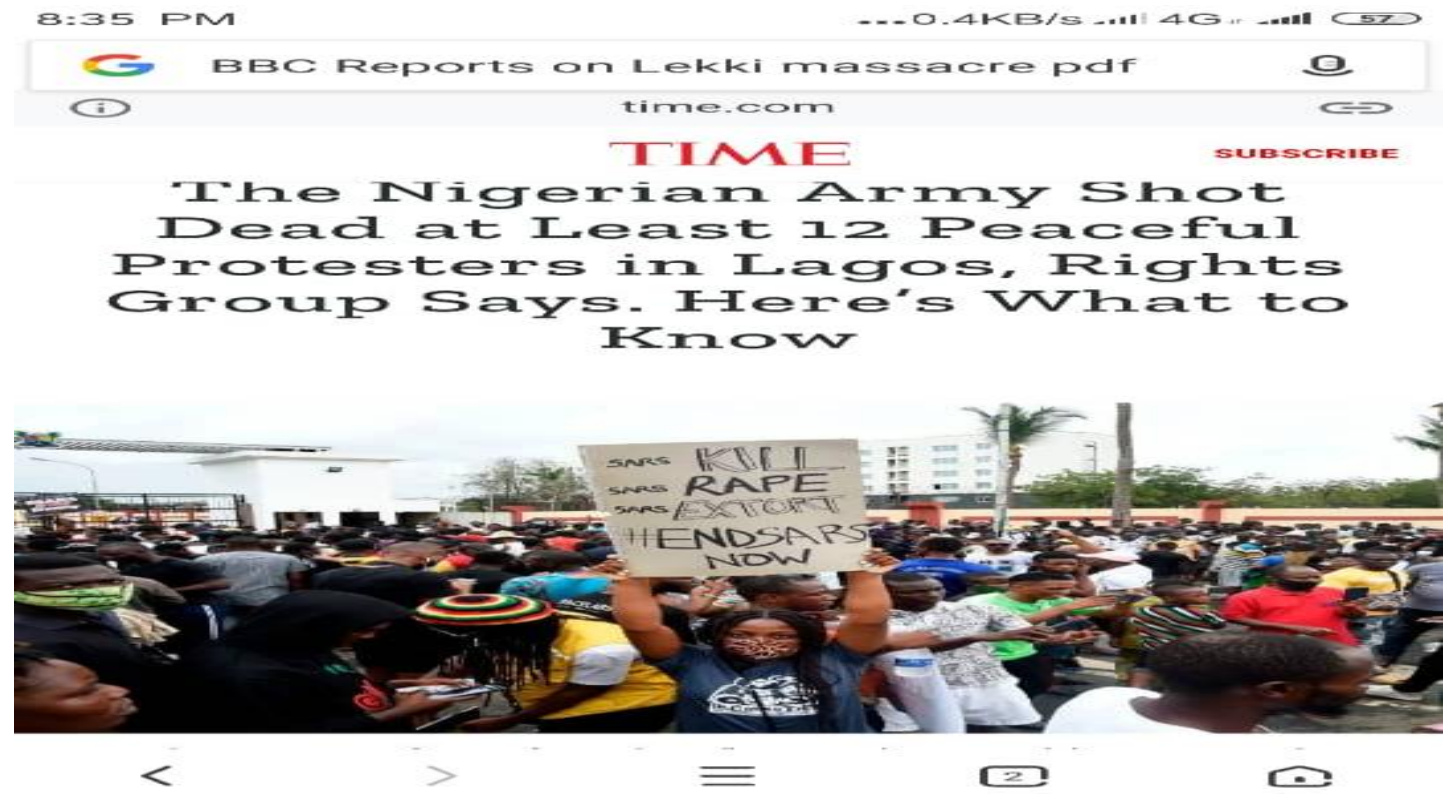

\section{Extract 2}

Examining this extract at sentence level of classification under sentiment analysis, shows the extract as an objective sentence because it presents some factual information about the reason(s)why these youths decided to go out on protest since there have been reports on unjustful killing of some people, rapes, extortion, etc. in the country at that crucial period and the government didn't deem it fit to find lasting solution to all these problems. The interpersonal relation reveals through the images and the texts in the extract shows a kind of familiarity between the viewers, the youths and the government since the protesters were able to bring out some of the things they don't want in the society again. The opinion mining of the readers of this extract will be negative since factual information is presented here. 

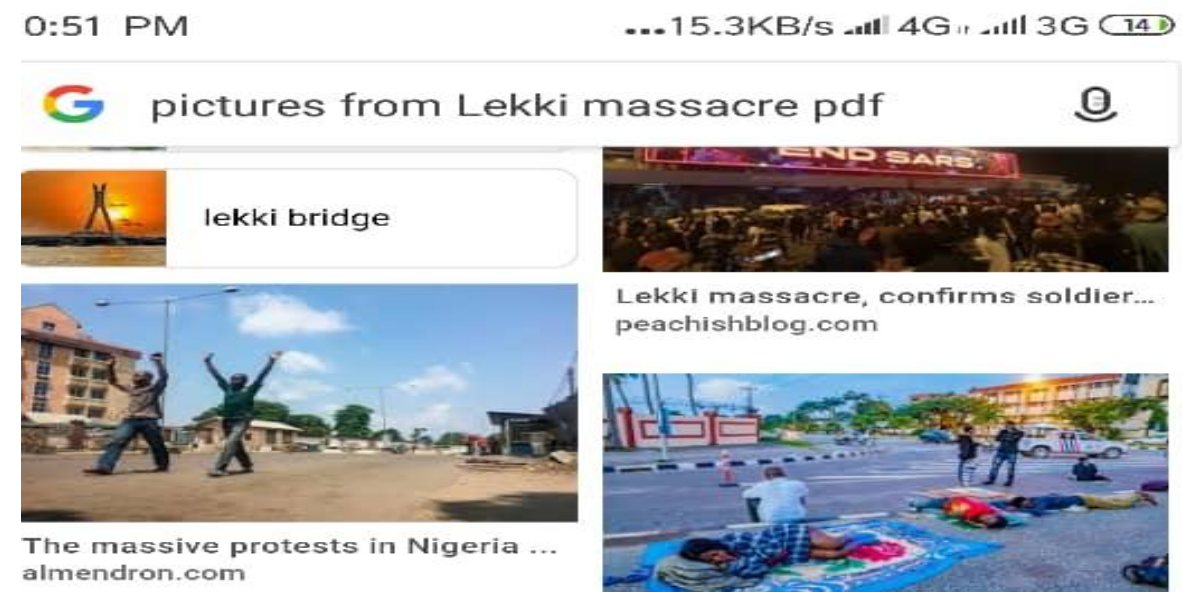

\section{Extract 3}

There are different messages presented to us inextract 3 , we can see the aggrieved youths who have turn the road into bedroom, Lekki toll bridge, and picture of many youth out there both at night and day. After reading or viewing this extract, there will be a kind of emotional feelings of pity and sympathy towards these youths. In this extract, sentiment is extracted from the entire review, that is the whole document and a whole opinion is classified based on the overall sentiment of the opinion holder which will be negative with the picture of the youth sleeping outside with cold at night and heat of the sun. The implication of this is that the viewer's either home or abroad will view the nonchalant attitude of the government as being inhuman to their subjects.

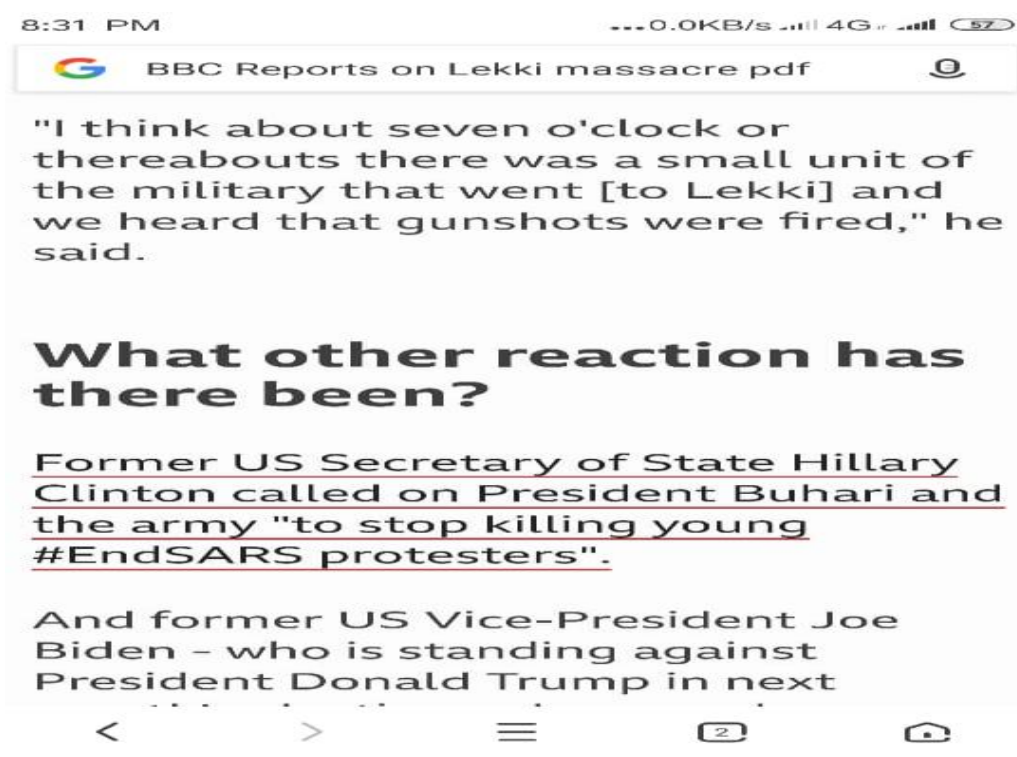

\section{Extract 4}

Extract 4 above reveals the opinion of US former Secretary Hillary Clinton and president elect who was one of the presidential candidates for 2020 US presidential election at that time calling out to the Nigeria president "to stop killing the young protesters". The statement of Hillary Clinton in the extract above is a subjective sentence under sentiment analysis, because it expresses personal feelings, view, emotion, andthe belief of the former US Secretary. Her emotional feelings, views and opinion is that these peaceful protesters should not be killed but be listened to and solution should be proffered for all their needs.

In addition, Joe Biden U.S 2020's presidential candidate urged Nigeria authorities to cease the "violent cracked down on protesters". There is negative sentiment value in the statement made by Joe Biden. Observing this from document level of sentiment classification, it is written by a single person (Joe Biden) and it expresses an opinion/sentiment on a single entity (Endsars issue). The implication of this is that, Joe Biden has negative opinion towards what the Nigeria authorities are doing to the 
youth at that particular time, so he employed them to stop the violent cracked down on the protesters. Besides this, the interpersonal relation between the Joe Biden and the Nigeria authorities here can be said to reflect inequality. The power relation between the speaker and the people the message is meant for (Nigeria authorities) is that of unequal relation.

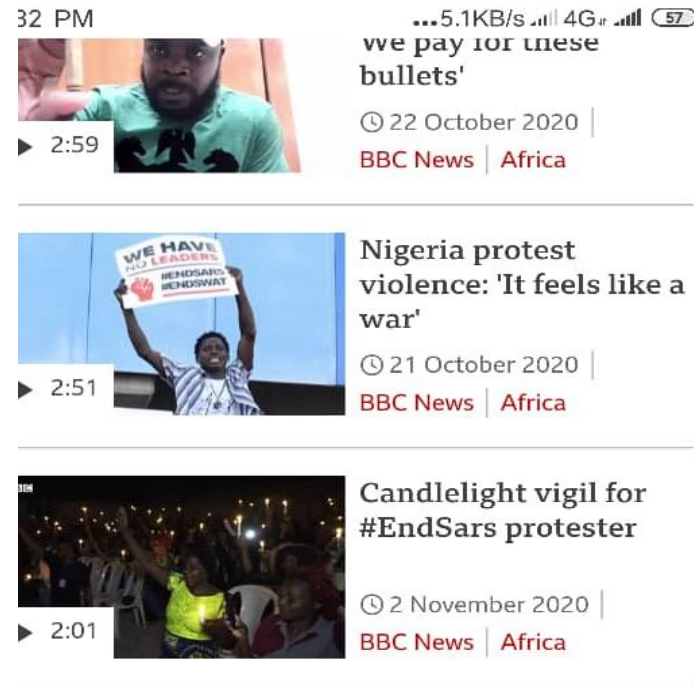

Extract 5

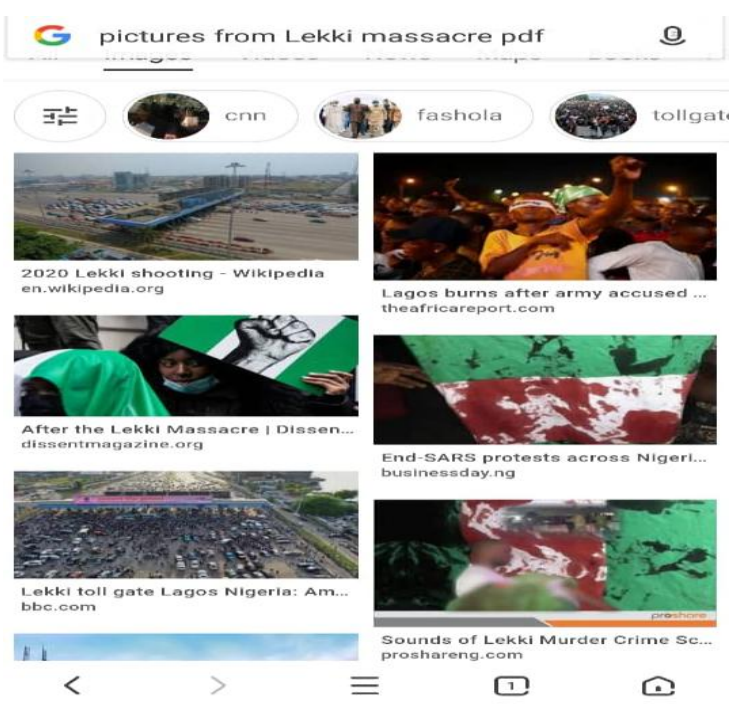

Extract 6

In extracts 5 and 6 above, the images and the texts all reveal negative opinion mining or negative sentiment about Lekki toll gate shooting. The extracts reveal candlelight vigil kept for the victims of Lekki shooting who lost their lives, Nigeria flag stained and soaked with innocent blood of the peaceful protesters, and the symbol of Endsars which is a folded arm. In extract 5, there is a picture of a youth holding a placard with caption "we have no leader". This is a subjective sentence under sentiment analysis. It reveals the feelings, views, and opinion of these youths because of the way they were being treated. The opinion here is negative because it is generally believed that if truly there are leaders, who have listening ears and see things from the perspective of the youths, things wouldn't be happening that way. The picture of the flag in extract 6 , with the stained blood, also reveals a negative reaction that the viewers will definitely have about the way the youths were being killed.

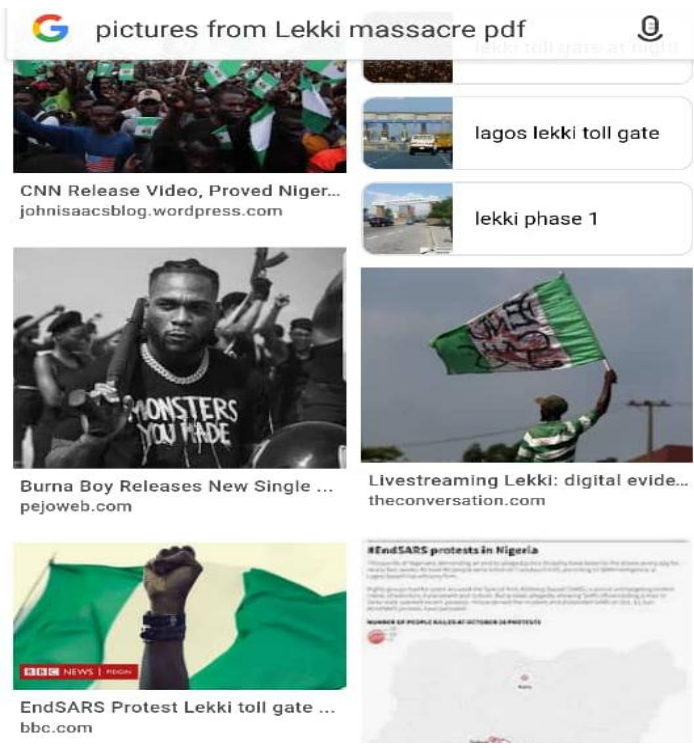

Extract 7

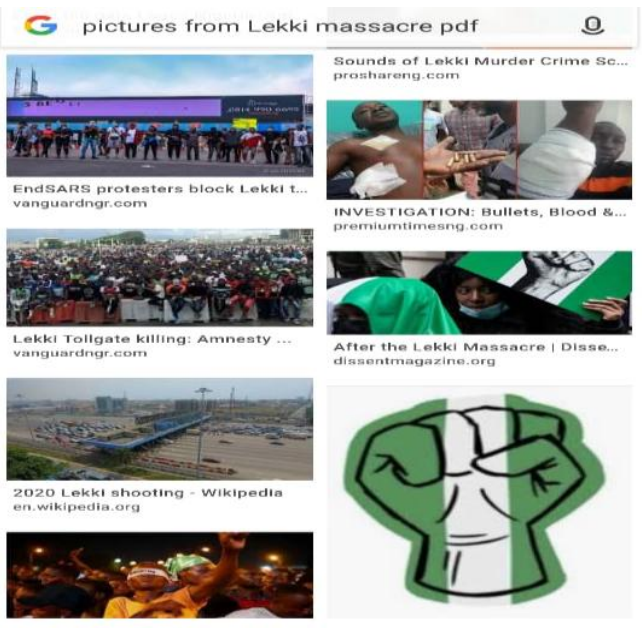

Extract 8

In addition, extracts 7 and 8 show the images of the youths holding the National flag and those who were wounded that were in the hospital. All these prove to the outside world that some of the youths were truly killed by the Nigeria Army. The pictures also reveal a kind of positive opinion about the unity that exists among the youths. The symbol of Endsars (folded) arm also speaks volume about their intention on Endsars matter. 


\section{Extract 9}

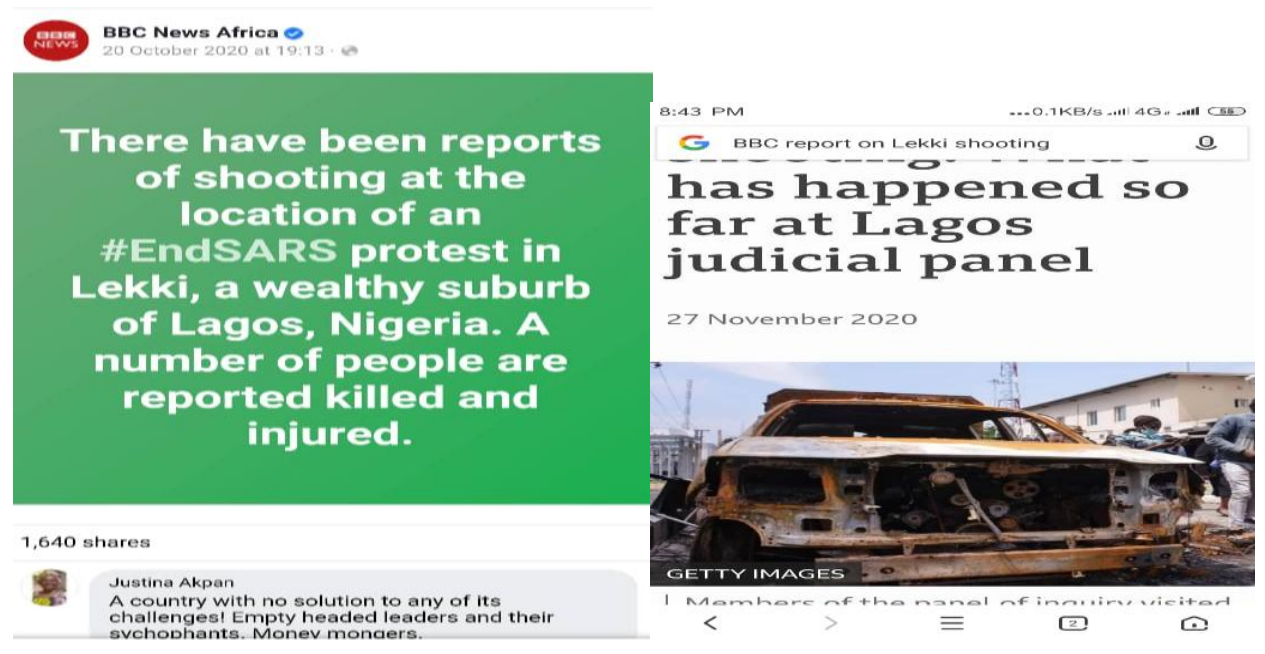

Furthermore, extract 10 is an example of objective sentence looking at the picture of the car burnt down by the protesters. It shows that, due to the killing of some of the youths, some public and private properties were destroyed and the Endsars protest led to the setting up of judicial panels to look into the matter.A kind of negative opinion will emerge,against the youths for taking laws into their hands by destroying the properties. Examining the response of one of the viewers inextract 9, named Justine Akpan, "A country with no solution to any of its challenges! Empty headed leaders and their sycophants. Money mongers". All these expressions give the true picture of the nation and the leaders. The opinion mining here is negative because viewers will definitely see the leaders being selfish and not concerned with state of the nation at large.

\section{CONCLuSion}

In conclusion, most of the analysisrevealed that majority of the viewers' opinion to the contents of the extracts is that of negative opinion mining or negative sentiment value about Lekki toll gate shooting. The attitude of Nigeria government towards their subjects, Nigeria Army's attitude of shooting the peaceful protesters, the way Nigeria youths destroyed some public and private properties all tailored towards negative sentiment value. Apart from these, the emotional feelings and views of those outside Nigeria (for example, US) also show negative sentiment value.Therefore, it is reasonable to conclude that the viewers' interpretations of BBC'S Endsars pictures/messages during Nigeria's youths Endsars have both negative and positive sentiment values, but the negative opinion mining is more than that of positive opinion mining. Extracts 7 and 8 only reveal a kind of positive opinion about the unity that exists among these youths. The symbol of Endsars (folded) arm also speaks volume about their intention that special Anti-Robbery squad or (SARS) should be scraped, because of the inhuman treatment of the youths.

In addition, the interpersonal relations between the participants reflect that of inequality. For example, the statement of Hillary Clinton and Joe Biden to the Nigeria authorities shows inequality. The power relation between the speaker and the people the message is meant for (Nigeria authorities and government) is that of unequal relation.

\section{REFERENCES}

[1] Abirami, A. M., \&Gayathri, V. (2017).A survey on sentiment analysis methods and approach. Paper presented at the 2016 Eighth International Conference on Advance Computing (ICoAC).

[2] Halliday, M. A. K. (1994). An Introduction to Functional Grammar. (2 ${ }^{\text {nd }}$ Ed.). London: Edward.

[3] Halliday, M.AK. (2004). An Introduction to Functional Grammar (Third Edition) London: Armold.

[4] Kautish, S. \&Kaur, R. (2017). Sentiment Analysis: From Theory to Practice. Balti: Republic of Moldova. LAMBERT Academic Publishing.

[5] Kaur, R. \&Kautish, S. (2019). Multimodal sentiment analysis: A survey and comparison. International Journal of Service Science, Management, Engineering, and Technology. Volume 10, Issue 2. April-June, 2019.Accessed from https://www.researchgate.net $>3309 \ldots$ On $6^{\text {th }}$ June, 2021.

[6] Kress, G. and van Leeuwen, T. (2006). Reading images: The Grammar of Visual Design. London: Routledge. 
[7] Liu Bing (2010). Sentiment analysis and subjectivity.In Handbook of Natural Language Processing.Second Edition, (Editors: N. Indurkhya\& F. J. Damerau). Retrieved on $29^{\text {th }}$ May, 2021 from http://www.cs.uic.edu>FBS.

[8] Liu Bing (2015). Sentiment analysis: Mining opinion, sentiments, and emotions. Cambridge: Cambridge University Press. Accessed from https://www.aclweb.org >ant... On $6^{\text {th }}$ June, 2021.

[9] Maryam B. (2017). Sentiment analysis at document level. Retrieved from https://www.researchgate.net/ publication/320729882 on 24th May, 2021.

[10] Matthiessen, C.M.I.M. (1995). Lexico-grammatical cartography: English System. Tokyo: International Language Sciences publishers.

[11] Obaidat, I., R. Mohawesh, M. Al-Ayyoub, A.S. Mohammad and Y. Jararweh, (2015).Enhancing the determination of aspect categories and their polarities in Arabic reviews using lexicon-based approaches. Proceedings of the IEEE Jordan Conference on Applied Electrical Engineering and Computing Technologies, Nov. 3-5, IEEE Xplore Press, Amman, Jordan, pp: 1-6. DOI: 10.1109/AEECT.2015.7360595

[12] Olateju, M. A., \&Oyebode, O. (2014).Introducing Multimodality.Ibadan: College Press and Publishers Limited.

[13] Rajput, A. (2019). Natural language processing, sentiment analysis and clinical analytics. Retrieved from https://arxiv.org>pdf on $6^{\text {th }}$ June, 2021.

[14] TiejianLuo\&GuandonjXu (2013).Sentiment analysis. Retrieved from https://www.researchgate.net/public ation/300495226 on 21st May, 2021.

\section{APPENDIX}
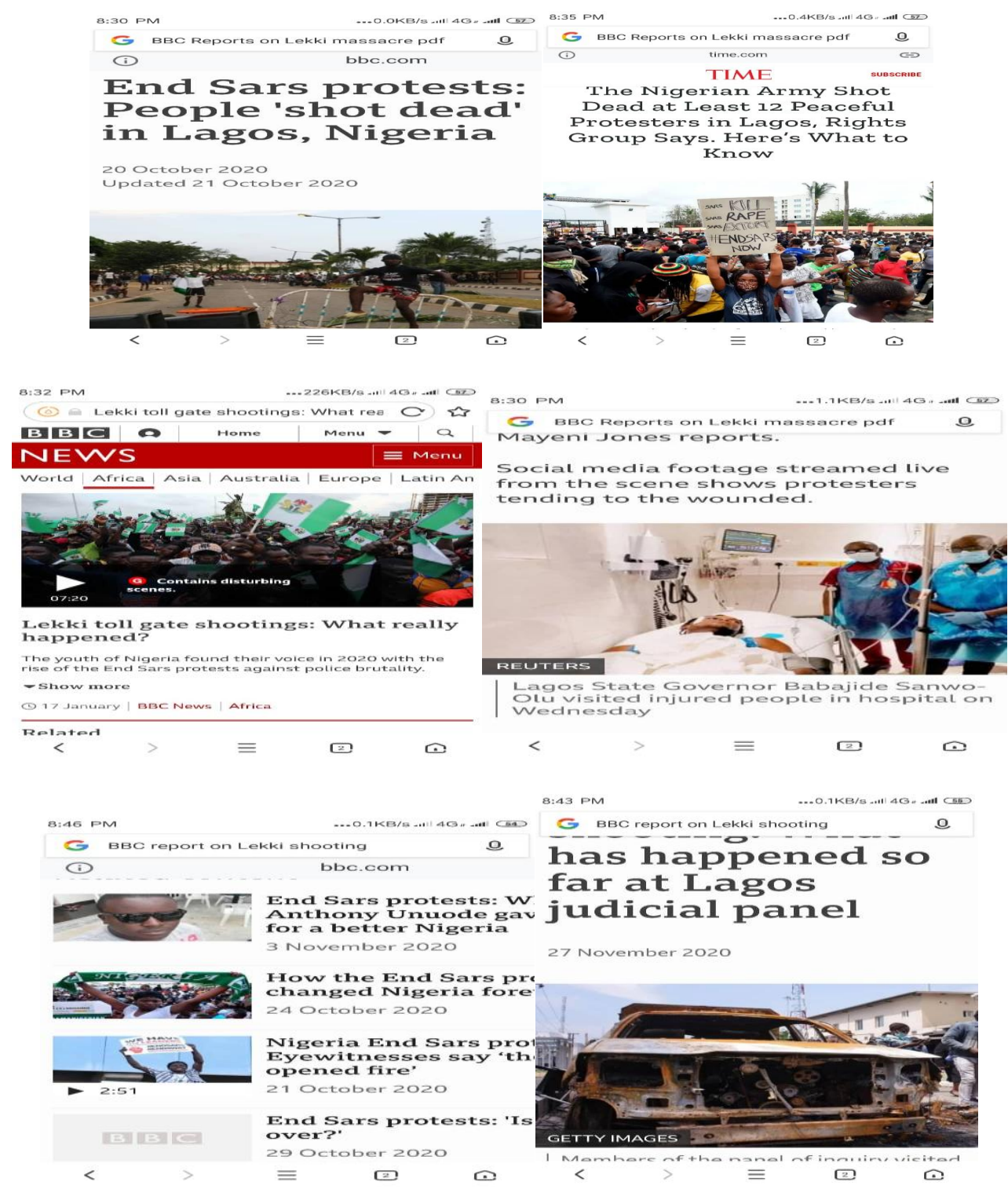

International Journal on Studies in English Language and Literature (IJSELL) 


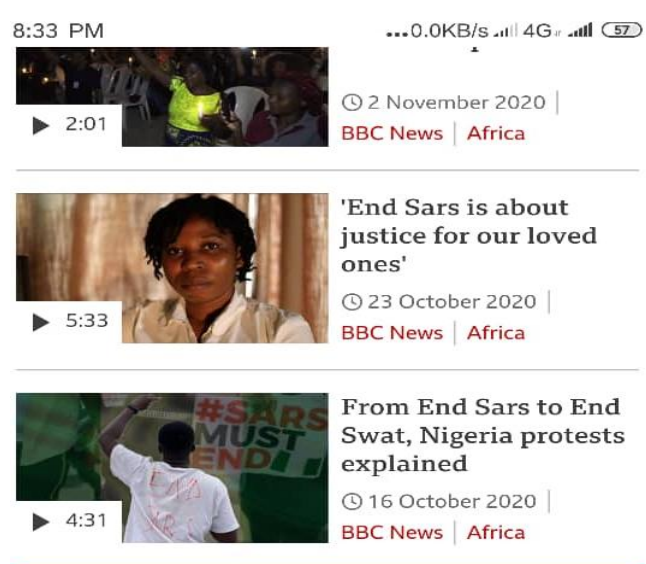

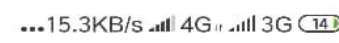

$0: 51 \mathrm{PM}$

$G$ pictures from Lekki massacre pdf $\quad 0$

G pictures from Lekki massacre pdf $\quad 0$

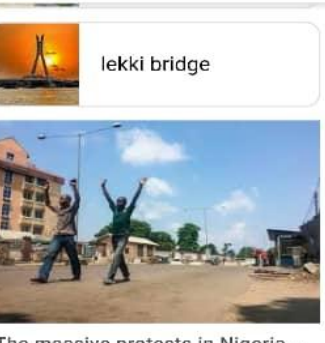

The massive protests in Nigeria ... almendron.com

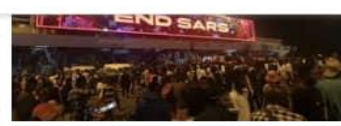

Lekki massacre, confirms soldier... peachishblog.com

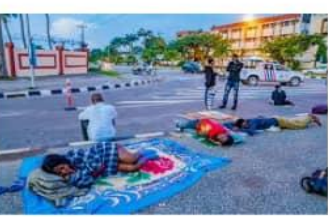

End SARS - Wikiwand wikiwand.com

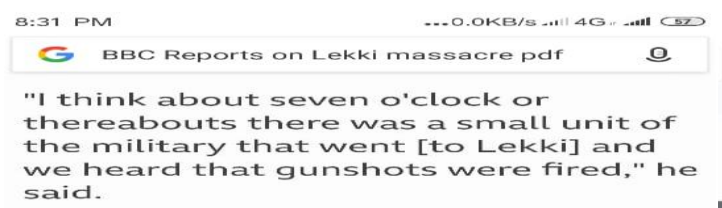

What other reaction has there been?

Former US Secretary of State Hillary Clinton called on president Buhari and the army "to stop killing young \#EndSARS protesters".

And former US Vice-President Joe Biden - who is standing against President Donald Trump in next

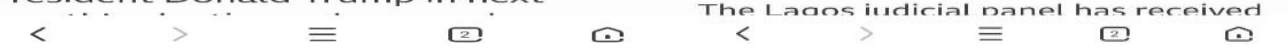

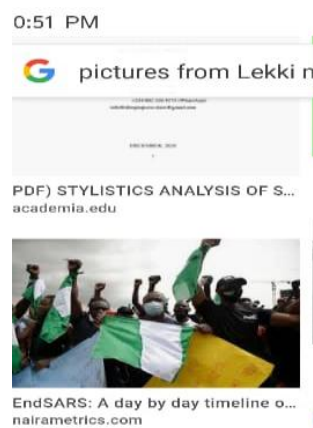

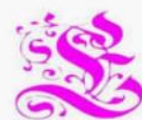

ELITE

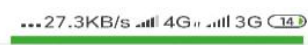

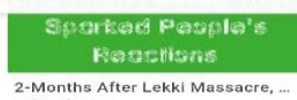

2-Months After Lekki Massacre,

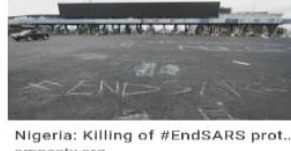

Nigeria: KIII
amnesty.org

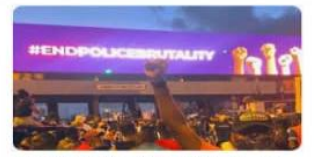

Nonathorities trying to co

Related searches

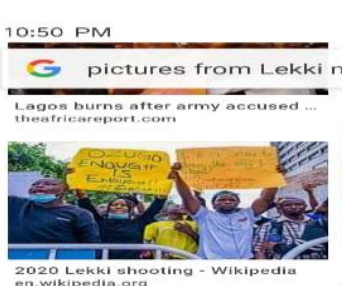

-.12.5kB/s,

(i)

trom civil society groups, the Human

Rights Commission, Citizens Mediation

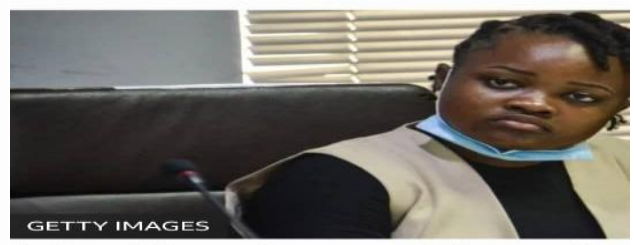

One of the youth representatives on the was a popular figure during the protests

$\equiv$
10:51 PM
.... $0.2 \mathrm{~KB} / \mathrm{s}$....1 $4 \mathrm{G}$.....11 $3 \mathrm{GC}$

nassacre pdf
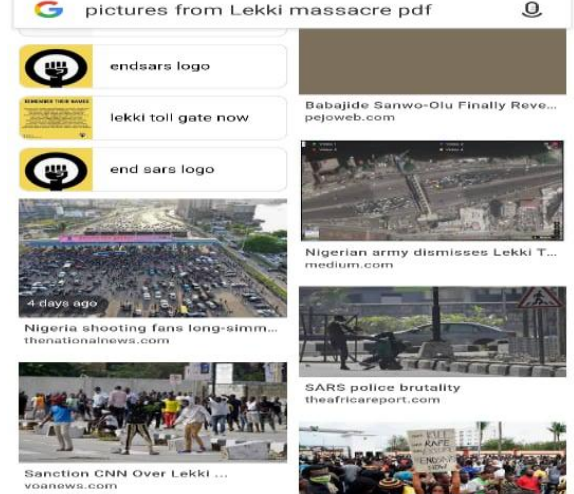

$<$

\section{(1)}
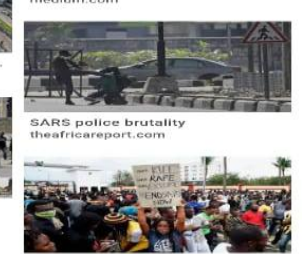

$\equiv$
17

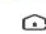
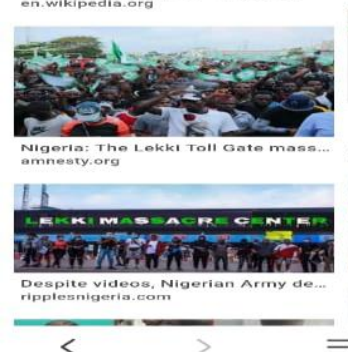

$=$
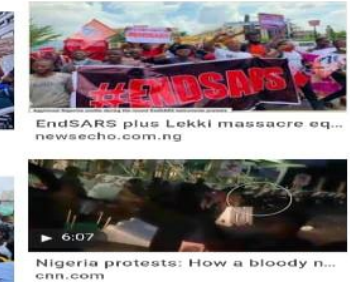

Nigeria protests: How
cnn.com

lekki toll gate

Grosasid lekki toll gate

arfubat lekki toll gat
shooting

The

$\odot$ 


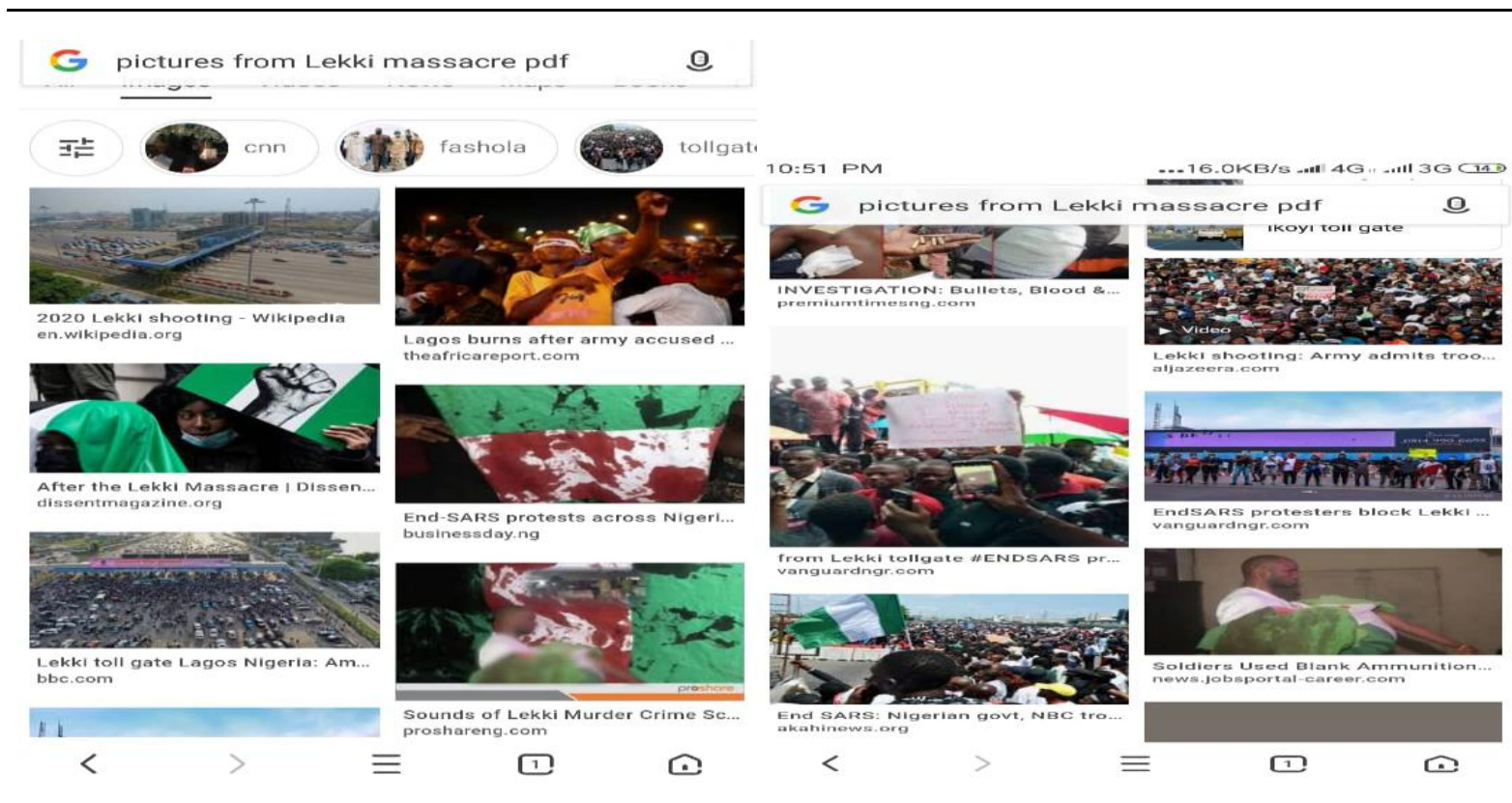

\begin{tabular}{|c|c|c|c|c|}
\hline \multicolumn{5}{|r|}{ KB $/ \mathrm{s}$} \\
\hline \multicolumn{5}{|c|}{$G$ BBC report on Lekki shooting } \\
\hline \multicolumn{5}{|c|}{ bbc.com } \\
\hline B & $B / C M$ & $\boldsymbol{v}=\boldsymbol{V}$ & is & \\
\hline$\equiv$ & Home & UK & World & Business \\
\hline
\end{tabular}

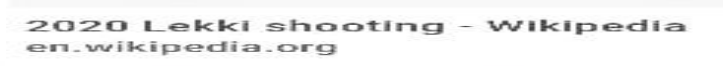

Nigeria's Lekki
shooting: What
has happened so
far at Lagos
judicial panel

ADVER
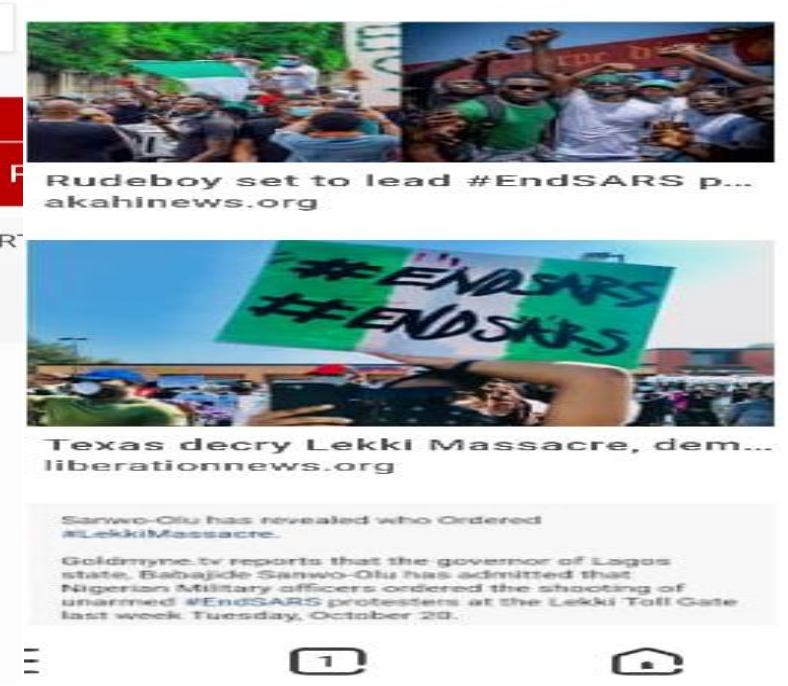

$<\quad>\quad 2$

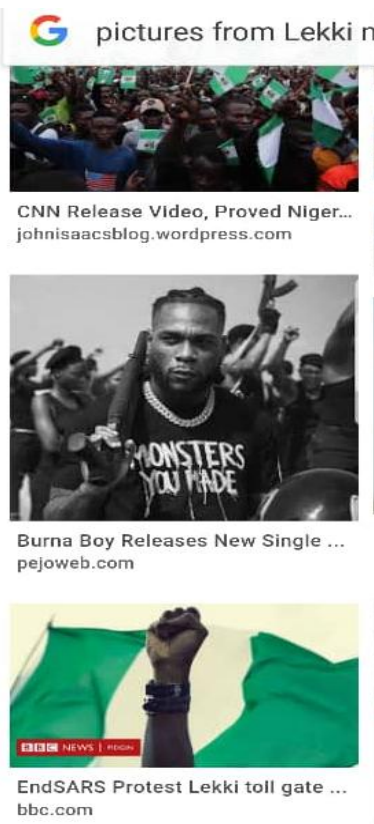

ㅂ.
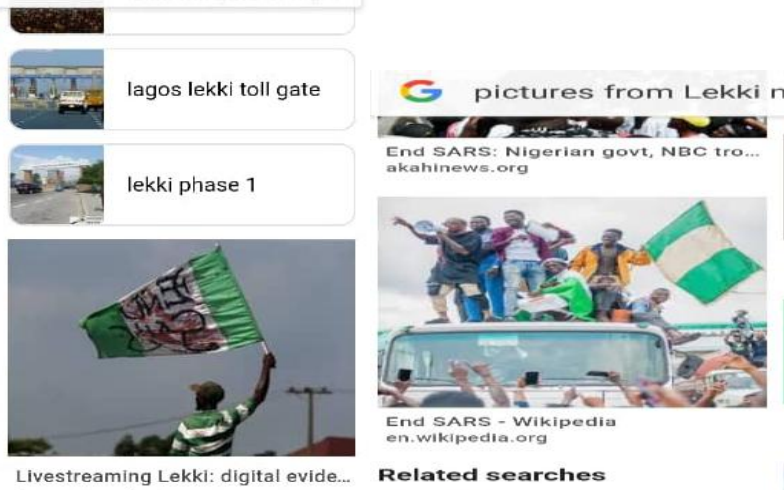

o
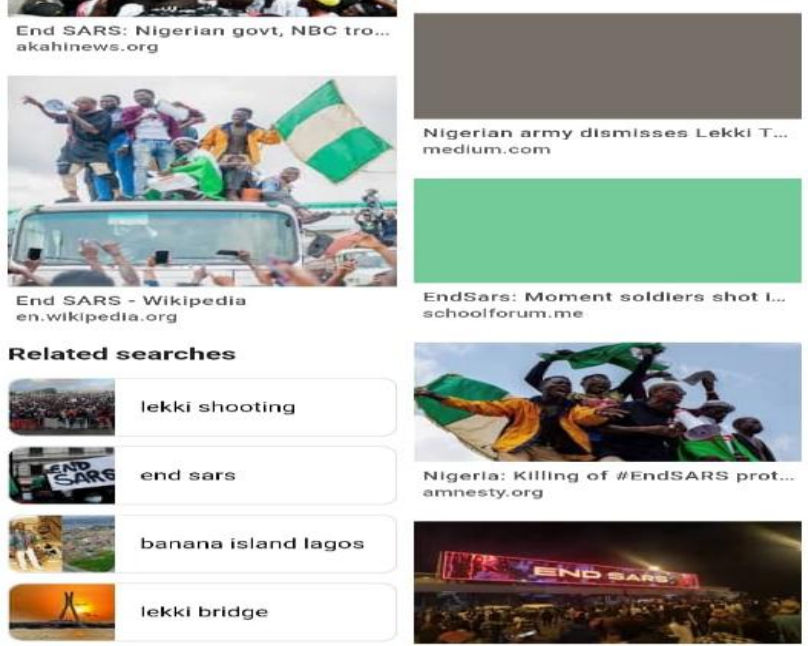

International Journal on Studies in English Language and Literature (IJSELL)

Page $\mid 90$ 

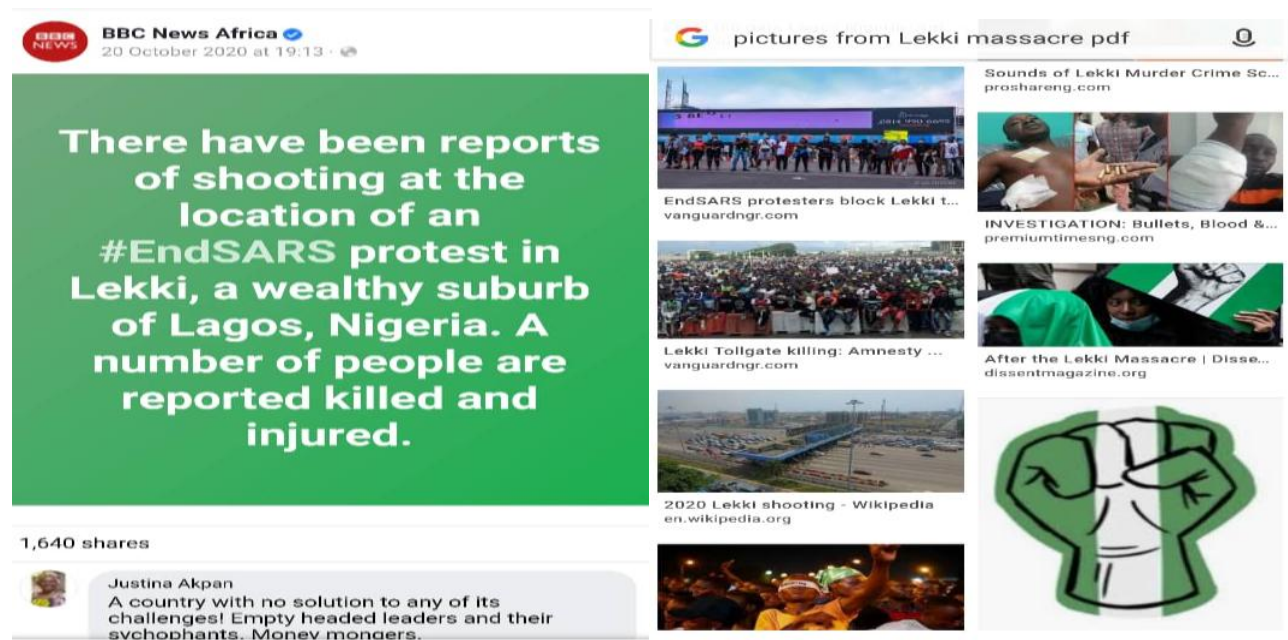

Citation: Ajepe, Ife Fiyinfolu, Aroge, Modupe Grace. "Multimodal Sentiment Analysis Of 2020 Endsars' Lekki Massacre” International Journal on Studies in English Language and Literature (IJSELL), vol 9, no. 7, 2021, pp. 80-91. doi: https://doi.org/10.20431/2347-3134.0907006.

Copyright: () 2021 Authors. This is an open-access article distributed under the terms of the Creative Commons Attribution License, which permits unrestricted use, distribution, and reproduction in any medium, provided the original author and source are credited. 